\title{
Use of waterpipes and other substances in adolescents: Prevalence and potential associations with mental and behavioral well-being, a cross-sectional study
}

\author{
Juan M. Sáenz-Lussagnet ${ }^{1,2}$, Fernando Rico-Villademoros ${ }^{3}$, Luis G. Luque-Romero ${ }^{1,4}$
}

\begin{abstract}
INTRODUCTION This study assess the prevalence and potential determinants (attitudes, behavioral and emotional conditions) associated with waterpipe tobacco smoking (WTS) and cigarette smoking in adolescents in public compulsory secondary schools.

METHODS This was a cross-sectional study conducted in October 2017 in three secondary schools from Seville, Spain, among adolescents aged 12-18 years. We administered an ad hoc questionnaire to explore the demographic and clinical characteristics of students; in addition, it included questions on consumption of tobacco (waterpipe and/or cigarette), alcohol (usual consumption and/or drunkenness) and/or cannabis, and attitudes towards waterpipe tobacco smoking. We also administered a validated version of the Strengths and Difficulties Questionnaire (SDQ), which is used to screen children and adolescents with emotional and behavioral problems. An established usage of a substance was defined as weekly or daily use. A multivariate analysis was performed using binary logistic regression methods to determine the probability of established usage. RESULTS Of the 1135 adolescents, $72.1 \%$ lived with at least one smoker; the established usage was $13.4 \%$ for waterpipe; $9.2 \%$ for cigarettes and $3.2 \%$ for dual use. Of those with established usage of waterpipe, $38.2 \%$ had established alcohol usage, $12.7 \%$ were drunk weekly or daily, and $27.4 \%$ used cannabis. Students consolidating the consumption of waterpipes were three times more likely to have established cigarette use than those not having an established usage $(\mathrm{OR}=3.7$; $\mathrm{p}=0.0005$ ). The overall SDQ score increased the likelihood of established usage of both waterpipes and cigarettes $(\mathrm{p}=0.0005)$.

CONCLUSIONS The probability of established usage of cigarettes (multivariate analysis) is associated with increasing age (course), cohabitation with smokers, established usage of waterpipe, established use of alcohol and a borderline score in the behavioral dimension (SDQ). Addiction to waterpipes among teens is significantly associated with their behavioral and emotional difficulties.
\end{abstract}

\section{AFFILIATION}

1 Aljarfe - Sevilla North District, Andalusian Health Service, Regional Council of Andalusia, Seville, Spain

2 Department of Evolutionary

Psychology and Education, Faculty of Psychology, Seville University, Seville, Spain

3 Federico Olóriz Neuroscience Institute, Granada University, Granada, Spain

4 Department of Normal and Pathological Cytology and Histology, Faculty of Medicine, Seville University, Seville, Spain

CORRESPONDENCE TO Juan M. Sáenz Lussagnet. North Aljarafe-Sevilla Health District, Andalusian Health Service, Regional Council of Andalusia, Virgen de Montserrat Street №3$5^{\circ} \mathrm{A}, 41011$, Seville, Spain. E-mail: juanmasaenz@hotmail.com ORCID ID: https://orcid.org/0000-00024002-9014

KEYWORDS

tobacco, waterpipe, adolescents, cigarette, health knowledge attitudes

Received: 30 November 2020

Revised: 29 March 2021

Accepted: 18 May 2021

\section{INTRODUCTION}

Since 2005, the World Health Organization and other agencies and experts have been noticing an increased prevalence in waterpipe tobacco smoking ${ }^{1,2}$, and in the health problems associated with this form of tobacco use $\mathrm{e}^{3-5}$, and on an increased risk of nicotine addiction in adolescents related to this way of tobacco consumption ${ }^{6,7}$, known as the 'gateway theory'.

A recent meta-analysis links the risk of starting the use of waterpipes with the risk of cigarette use ${ }^{8}$, while a waterpipe session exposes the individual to smoke and toxic levels higher than those of 
cigarettes $^{9,10}$.

Globally, there is consensus that waterpipe use is becoming a widespread worldwide problem, especially among young people, and that it poses a new threat in the global fight against smoking and its consequences in terms of morbidity and mortality ${ }^{11}$.

This form of smoking, especially among young people, is outperforming cigarette use, not only in Middle Eastern countries but also in some Western countries such as the United Kingdom and Spain ${ }^{12,13}$. The study on lifestyles Health Behavior in Schoolaged Children (HBSC) 2018, in which 17507 adolescents aged 15-18 years were surveyed from all over Spain (the largest sample on waterpipe use) indicates that $19.1 \%$ of adolescents have used waterpipes sometime in their life $\mathrm{e}^{12}$. Longitudinal studies on the use of waterpipes in adolescents in the USA show notable increase and fluctuations ${ }^{14}$.

Regarding risk factors for waterpipe tobacco smoking (WTS), Pratiti and Mukherjee ${ }^{3}$ grouped them into three categories: factors related to the substance (agent), environmental factors, and factors related to the individual (host). While factors related to substance and environment are well established, factors related to the individual are still understudied $^{3}$, especially those related to adolescent mental health ${ }^{15,16}$ and new forms of nicotine intake (waterpipes and e-cigarettes).

Therefore, and within the framework of a project on the prevention of tobacco use in adolescents, this cross-sectional study was conducted to assess the prevalence and potential determinants (attitudes, behavioral and emotional conditions) associated with tobacco use in waterpipes and cigarettes in adolescents in public secondary schools in the south of Spain.

\section{METHODS}

This cross-sectional study was conducted in October 2017 in three secondary schools (IES) selected based on their accessibility and sociodemographic profile (rural populations of the north-western part of Seville province, in the south of Spain). Schools participating in this Project were: IES La Algaba, IES Castilblanco de los Arroyos, and IES de Gerena. All students of first to fourth grade of compulsory secondary education (ESO) and first to second grade of high school (Bach) present on the day of the survey administration were invited to anonymously and voluntarily participate. The study was approved by the School Board of each participating IES and by the Research Ethics Committee of the Reference Hospitals.

\section{Assessment tools}

An ad hoc 23-item self-administered questionnaire was developed following expert recommendations on how to ask adolescents about waterpipe use ${ }^{11}$, which includes questions about: essential use, dependence or cessation, exposure (current smokers), expanded use related items and policy/regulation related items. The questionnaire collected information about the student's age and gender, cigarette use in coexistent relatives, frequency of tobacco use (cigarettes and waterpipes) of the student, and the attitudes regarding WTS. It also asked about the use of alcohol and other substances such as cannabis (Annex 1). In addition, Goodman's questionnaire 'The Strengths and Difficulties Questionnaire' (SDQ) (translated into Spanish and validated), used to screen children and adolescents with emotional and behavioural problems was also administered; In addition to a total score, the 25 items provide information on five dimensions: emotional symptoms subscale, conduct problems subscale, hyperactivity/inattention subscale, peer problem subscale, and prosocial behaviour subscale $^{17-20}$. Questionnaires were handed over and explained by the tutors of the different groups during a normal class (50 min). The teachers in charge of administering the survey had been previously trained by the researchers to solve the possible doubts of the students without giving leading answers.

Sociodemographic variables such as age, course, sex, and cohabitation with smoker relatives and their kinship were analysed. In addition, the use of substances (cigarettes, waterpipe, alcohol, drunk and cannabis) was also assessed: the age of initiation and the frequency of consumption. We defined 'drunk or dizzy from alcohol' as the adolescent's self-perception in response to the question: 'Have you ever been drunk or dizzy from alcohol?' Attitudes and beliefs regarding waterpipe use were also measured. Finally, emotional and behavioural abilities and difficulties were analysed using the SDQ questionnaire. The established usage of cigarettes, waterpipes, alcohol, drunk or dizzy from alcohol and experience with cannabis were used as variables. 
Substance use was classified as 'established' if weekly or daily; 'sporadic' ('once in a while'), for cigarettes, and 'unestablished' for monthly or sporadic use of waterpipes, alcohol or drunk or dizzy from alcohol. Cannabis use was classified as 'experienced' or 'not experienced' (having smoked at least once). SDQ questionnaire scores, both global and by dimensions, were expressed as the median and interquartile range (IQR: P25-P75) and subsequently, to improve comparability with other studies, the overall SDQ score was encoded into three categories (cut-off points: normality -from 0 to 15 points-, borderline -from 16 to 19 points- and pathological -from 20 to 40 points-) following the rules of the questionnaire itself ${ }^{21}$.

A descriptive analysis and subsequently a bivariate analysis of data were performed. The chi-square test was used to determine the association between two qualitative variables as determinants of cigarette and waterpipe use. The mean comparisons were made using the Student's t-test, and asymmetric distributions were compared using Mann-Whitney's U test. With variables whose significance was less than 0.15 , a binary logistic regression model was used to evaluate the association of explanatory variables with the established usage of cigarettes, which is the greater consumption in adulthood and therefore indicates the risk of later smoking. All tests were bilateral and were considered significant if $\mathrm{p}<0.05$.

Data were analysed using the IBM-SPSS v.22 and EPIDAT 3.1 statistical software.

\section{RESULTS}

\section{Subjects disposition and characteristics}

The sample size was $n=1135$ students: $876(77.2 \%)$ were ESO (middle school) students and 259 (22.8\%) were high school students. The average age (SD) was 14.7 (1.8) years. Of the total, 546 (48.1\%) were female students, and 47 (4.1\%) did not answer the gender question. The characteristics of these students are shown in Table 1.

\section{Prevalence and use initiation}

In terms of the prevalence of substance use, 152 (13.4\%) had established waterpipe usage and 104 (9.2\%) established cigarette usage. Globally, 230 $(20.2 \%)$ had established tobacco usage in one form, and $36(3.2 \%)$ had established usage in both. Of those with established usage of waterpipe, $60(38.2 \%)$ had established use of alcohol, 20 (12.7\%) were drunk or dizzy from alcohol on a weekly or daily basis and $43(27.4 \%)$ used cannabis. Similarly, of those with established usage of cigarettes, $51(46.8 \%)$ were established alcohol users, 26 (23.9\%) established drunk and 59 (54.1\%) used cannabis; all these associations are statistically significant (Table 1). Students with established usage of waterpipes have a threefold greater chance of having established usage of cigarette ( $\mathrm{OR}=3.7$; 95\% CI: $2.4-5.7, \mathrm{p}=0.0005)$.

There is a progression in the age of use initiation in such a way that the average (standard deviation) [95\% CI age of use initiation of alcohol is 13.6 (1.6)] (95\% CI: 13.5-13.7); of waterpipe, 13.9 (1.7) (95\% CI: $1.8-1114.0$ ), of cigarettes 14.2 (1.7) (95\% CI: 14.1-14.3) and cannabis 14.6 (1.7) (95\% CI: $14.5-14.7)$ years $(p=0.0005)$. In order to identify the existence of differences in usage distributions per course, a paired comparison of substances was conducted using the Mann-Whitney U test, which highlighted the existence of these significant differences $(p=0.0005)$.

\section{Potential determinants on substances use}

Family role model (cohabitation with smokers)

From our sample, 818 (72.1\%) students lived with at least one smoker. Of these, $120(14.7 \%)$ had established usage of waterpipe and $90(11.0 \%)$ cigarette $(p=0.189$; and $p=0.01$ compared with the established usage of those not living with a smoker, respectively) (Table 1 ).

A statistically significant association was found among female students living with smokers and the established usage of cigarette [43 (11.1\%) established users vs $8(5.0 \%)$ non-established users $(p=0.025)]$. This behaviour was not seen in males.

We have also analysed the differential role of cohabitants, classifying them into the following categories (father, mother, sister, brother, grandfather, grandmother and others). If the mother smokes, the risk of established cigarette use among adolescents increases ( $\mathrm{OR}=1.96 ; 95 \% \mathrm{CI}: 1.31$ $2.92, \mathrm{p}=0.0012$ ), and if it is the sister who smokes, the probability is increased more than threefold $(\mathrm{OR}=3.73: 95 \%$ CI: 1.81-7.67, $\mathrm{p}=0.0004)$. No statistically significant differences were seen in the rest of the family members. 
Cognitive attitudes associated with waterpipe usage

With regard to cognitive attitudes (beliefs) associated with WTS, it should be noted that there are statistically significant differences between students who had established usage and those who did not. The former showed beliefs and cognitive attitudes consistent (understanding as consistent, favourable attitudes to consumption) with minor damages (waterpipe and cigarette) (Table 1).

\section{Cognitive-behavioural difficulties and strengths}

Within the analysis of emotional and behavioural variables associated with established usage of waterpipe and cigarette, we found that the overall

Table 1. Demographic, clinical characteristics and attitudes towards waterpipe tobacco smoking of secondary school students from Seville, Spain, October 2017 ( $N=1135)$ : overall and by the degree of tobacco usage in waterpipe or cigarette

\begin{tabular}{|c|c|c|c|c|c|c|c|}
\hline \multirow[t]{2}{*}{ Variables } & \multirow[t]{2}{*}{ Total } & \multicolumn{3}{|c|}{ Waterpipe usage } & \multicolumn{3}{|c|}{ Cigarette usage } \\
\hline & & $\begin{array}{c}\text { Not } \\
\text { established } \\
(\mathbf{9 7 8 ; 8 6 . 2 \% )}\end{array}$ & $\begin{array}{l}\text { Established* } \\
(157 ; 13.8 \%)\end{array}$ & $p$ & $\begin{array}{c}\text { Not } \\
\text { established } \\
(1026 ; 90.4 \%)\end{array}$ & $\begin{array}{l}\text { Established* } \\
(109 ; 9.6 \%)\end{array}$ & $p$ \\
\hline Age (years), mean (IOR) & $14.5(13.2-16.3)$ & $14.3(13.1-16.0)$ & $16.0(14.5-17.0)$ & $<0.001$ & $14.4(13.1-16.1)$ & $16.0(14.8-16.9)$ & 0.0005 \\
\hline Sex, $n(\%)^{a}$ & & & & 0.148 & & & 0.806 \\
\hline Female & $546(50.2)$ & $478(51.1)$ & $68(44.7)$ & & $495(50.3)$ & $51(49.0)$ & \\
\hline Male & $542(49.8)$ & $458(48.9)$ & $84(55.3)$ & & $489(49.7)$ & $53(51.0)$ & \\
\hline School grade $(\mathrm{Br} \text {, age })^{b}, \mathrm{n}(\%)$ & & & & 0.0005 & & & 0.0005 \\
\hline 1st ESO (8th year, 12-13) & $244(21.5)$ & $235(24.0)$ & $9(5.7)$ & & $240(23.4)$ & $4(3.7)$ & \\
\hline 2nd ESO (9th year, 13-14) & $248(21.9)$ & $225(23.0)$ & $23(14.6)$ & & $231(22.5)$ & $17(15.6)$ & \\
\hline 3rd ESO (10th year, 14-15) & $206(18.1)$ & $183(18.7)$ & $23(14.6)$ & & $181(17.6)$ & $25(22.9)$ & \\
\hline 4th ESO (11th year, 15-16) & $178(15.7)$ & $140(14.3)$ & $38(24.2)$ & & $152(14.8)$ & $26(23.9)$ & \\
\hline 1st Bachiller (12th year, 16-17) & $147(13.0)$ & $114(11.7)$ & $33(21.0)$ & & $125(12.2)$ & $22(20.2)$ & \\
\hline 2nd Bachiller (13th year, 17-18) & $112(9.9)$ & $81(8.3)$ & $31(19.7)$ & & $97(9.5)$ & $15(13.8)$ & \\
\hline Cohabitation with smokers, n (\%) & $818(72.1)$ & $698(85.3)$ & $120(14.7)$ & 0.189 & $728(89.0)$ & $90(11.0)$ & 0.01 \\
\hline \multicolumn{8}{|l|}{ SD0 score, mean (IOR) } \\
\hline Emotional symptoms & $3.0(1.0-4.0)$ & $2.0(1.0-4.0)$ & $3.0(2.0-5.0)$ & 0.04 & $3.0(1.0-4.0)$ & $3.0(1.0-4.0)$ & 0.62 \\
\hline Behavioral problems & $2.0(1.0-3.0)$ & $2.0(0.0-3.0)$ & $2.0(1.0-4.0)$ & 0.0005 & $2.0(0.0-3.0)$ & $3.0(1.0-4.0)$ & 0.0005 \\
\hline Hyperactivity & $4.0(2.0-5.0)$ & $4.0(2.0-6.0)$ & $5.0(3.0-6.0)$ & 0.005 & $4.0(2.0-6.0)$ & $5.0(4.0-7.0)$ & 0.0005 \\
\hline Peer problems & $1.0(0.0-2.0)$ & $1.0(0.0-2.0)$ & $1.0(1.0-2.0)$ & 0.02 & $1.0(0.0-2.0)$ & $1.0(1.0-2.0)$ & 0.05 \\
\hline Prosocial behavior & $8.0(7.0-9.0)$ & $9.0(7.0-9.0)$ & $8.0(7.0-10.0)$ & 0.42 & $9.0(7.0-10.0)$ & $8.0(7.0-9.0)$ & 0.017 \\
\hline Total of difficulties & $10.0(6.0-14.0)$ & $10.0(6.0-14.0)$ & $12.0(8.0-15.0)$ & 0.0005 & $10.0(6.0-14.0)$ & $12.0(10.0-16.0)$ & 0.0005 \\
\hline Established use of alcohol, $n(\%)$ & $156(13.7)$ & $96(9.8)$ & $60(38.2)$ & 0.0005 & $105(10.2)$ & $51(46.8)$ & 0.0005 \\
\hline Drunk or dizzy from alcohol, n (\%) & $50(4.4)$ & $30(3.1)$ & $20(12.7)$ & 0.0005 & $24(2.3)$ & $26(23.9)$ & 0.0005 \\
\hline THC usage, $n(\%)$ & $117(10.3)$ & $74(7.6)$ & $43(27.4)$ & 0.0005 & $58(5.7)$ & $59(54.1)$ & 0.0005 \\
\hline \multicolumn{8}{|l|}{ Cognitive attitudes, n (\%) } \\
\hline Damage by WP $\geq$ cigarette & $243(21.4)$ & $220(22.5)$ & $23(14.7)$ & 0.0005 & $213(20.8)$ & $30(27.5)$ & 0.0005 \\
\hline Water filters toxic substances & $430(37.9)$ & $363(37.1)$ & $67(42.7)$ & 0.014 & $369(36.0)$ & $61(56.0)$ & 0.0005 \\
\hline WP affects passive smokers & $609(53.7)$ & $545(55.7)$ & $64(40.8)$ & 0.0005 & $559(54.5)$ & $50(45.9)$ & 0.002 \\
\hline WP transmits infections & $872(76.8)$ & 749 (76.6) & $123(78.3)$ & 0.307 & $786(76.6)$ & $86(78.9)$ & 0.075 \\
\hline Package contains information & $284(25.0)$ & $564(57.7)$ & $69(43.9)$ & 0.0005 & $235(22.9)$ & $49(45.0)$ & 0.0005 \\
\hline WP creates addiction & $633(55.8)$ & $564(57.7)$ & 69 (43.9) & 0.0005 & $581(56.6)$ & $52(47.7)$ & 0.0005 \\
\hline WP leads to cigarette use & $740(65.2)$ & $678(69.3)$ & $62(39.5)$ & 0.0005 & $666(64.9)$ & 74 (67.9) & 0.573 \\
\hline
\end{tabular}

* Established usage: waterpipe or cigarette use once of more times a week. a 147 (4.1\%) students did not answer the question about sex. IQR: interquartile range (P25-P75). b School grade: Expressed in the Spanish system, and in brackets the British equivalent (Br) and the age at which it is studied. ESO: mandatory secondary education. SDO: The Strengths and Difficulties Questionnaire. THC: tetrahidrocannabinol (cannabis). WP: waterpipe. 
score obtained in the SDQ questionnaire was positively associated with the established usage of both, waterpipe and cigarette $(\mathrm{p}=0.0005$ for both associations). When analysing the five dimensions of this questionnaire separately we found that the established use of waterpipe was positively and statistically significantly associated with emotional symptoms, behavioural problems, hyperactivity and peer problems. This same analysis for cigarette use revealed that this habit was positively and statistically significantly associated with behavioural problems, hyperactivity and difficulties related to prosocial behaviour. The analysis of the relationship between the established usage of waterpipe and cigarette and the SDQ questionnaire score by ranges is shown in Table 2.

However, difficulties related to prosocial behaviour have only been linked to cigarette use, whereas emotional symptoms were related only to waterpipe use (Table 1). Of the 1135 students who answered the SDQ questionnaire, 62 (5.5\%) had an overall score within the pathological range, and 127 (11.2\%) were borderline. By dimensions, the pathological range in emotional symptoms was higher in women than in men $(4.9 \%$ vs $2.6 \%$; $\mathrm{p}=0.009)$; behavioural problems in women were

Table 2. Distribution of score ranges in the Strengths and Difficulties Questionnaire among secondary school students from Seville, Spain, October 2017 ( $\mathrm{N}=1135$ ) according to gender and the established usage of tobacco in waterpipe or cigarette

\begin{tabular}{|c|c|c|c|c|c|c|c|c|c|}
\hline \multirow[t]{2}{*}{ Scores } & \multicolumn{3}{|c|}{$\operatorname{Sex}^{a}$} & \multicolumn{3}{|c|}{ Waterpipe usage } & \multicolumn{3}{|c|}{ Cigarette usage } \\
\hline & $\begin{array}{l}\text { Female } \\
(546 ; \\
50.2 \%) \\
n(\%)\end{array}$ & $\begin{array}{c}\text { Male } \\
(542 ; \\
49.8 \%) \\
n(\%)\end{array}$ & $p$ & $\begin{array}{c}\text { Not } \\
\text { established } \\
(978 ; 86.2 \%) \\
n(\%)\end{array}$ & $\begin{array}{c}\text { Established* } \\
(157 ; 13.8 \%) \\
n(\%)\end{array}$ & $p$ & $\begin{array}{c}\text { Not } \\
\text { established } \\
(1026 ; 90.4 \%) \\
n(\%)\end{array}$ & $\begin{array}{c}\text { Established* } \\
\begin{array}{c}(109 ; 9.6 \%) \\
n(\%)\end{array}\end{array}$ & $p$ \\
\hline SD0 total score ${ }^{b}$ & & & 0.443 & & & 0.033 & & & 0.0001 \\
\hline Normal (0-15) & $459(84.1)$ & $450(83.0)$ & & $833(85.2)$ & $125(79.6)$ & & $877(85.5)$ & $81(74.3)$ & \\
\hline Borderline (16-19) & $63(11.5)$ & $59(10.9)$ & & $100(10.2)$ & $17(10.8)$ & & $94(9.2)$ & $23(21.1)$ & \\
\hline Pathological (20-40) & $24(4.4)$ & $33(6.1)$ & & $45(4.6)$ & $15(9.6)$ & & $55(5.3)$ & $5(4.6)$ & \\
\hline Emotional symptoms & & & 0.009 & & & 0.277 & & & 0.321 \\
\hline Normal (0-5) & $450(82.4)$ & $479(88.4)$ & & $842(86.1)$ & $130(82.8)$ & & 875 (85.3) & $97(89.0)$ & \\
\hline Borderline (6) & $43(7.9)$ & $35(6.5)$ & & $65(6.6)$ & $16(10.2)$ & & $73(7.1)$ & $8(7.3)$ & \\
\hline Pathological (7-10) & $53(9.7)$ & $28(5.2)$ & & $71(7.3)$ & $11(7.0)$ & & $78(7.6)$ & $4(3.7)$ & \\
\hline Behavioral problems & & & 0.005 & & & 0.0005 & & & 0.0005 \\
\hline Normal (0-3) & $489(89.6)$ & $430(79.3)$ & & $837(85.6)$ & $114(72.6)$ & & $876(85.4)$ & 75 (68.8) & \\
\hline Borderline (4) & $38(7.0)$ & $51(9.4)$ & & $79(8.1)$ & $18(11.5)$ & & $80(7.8)$ & $17(15.6)$ & \\
\hline Pathological (5-10) & $19(3.5)$ & $61(11.3)$ & & $62(6.3)$ & 25 (15.9) & & $70(6.8)$ & $17(15.6)$ & \\
\hline Hyperactivity & & & 0.247 & & & 0.303 & & & 0.008 \\
\hline Normal (0-5) & $405(74.2)$ & 381 (70.3) & & $753(77.0)$ & 112 (71.3) & & 795 (77.5) & $70(64.2)$ & \\
\hline Borderline (6) & $63(11.5)$ & $80(14.8)$ & & $106(10.8)$ & $21(13.4)$ & & $109(10.6)$ & $18(16.5)$ & \\
\hline Pathological (7-10) & $78(14.3)$ & $81(14.9)$ & & 119 (12.2) & $24(15.3)$ & & $122(11.9)$ & 21 (19.3) & \\
\hline Peer problems & & & 0.418 & & & 0.628 & & & 0.147 \\
\hline Normal (0-3) & $494(90.5)$ & 477 (88.0) & & 877 (89.7) & 137 (87.3) & & 914 (89.1) & 100 (91.7) & \\
\hline Borderline (4-5) & $37(6.8)$ & 47 (8.7) & & $74(7.6)$ & $14(8.9)$ & & 79 (7.7) & $9(8.3)$ & \\
\hline Pathological (6-10) & $15(2.7)$ & $18(3.3)$ & & $27(2.8)$ & $6(3.8)$ & & $33(3.2)$ & $0(0.0)$ & \\
\hline Prosocial behavior & & & 0.005 & & & 0.03 & & & 0.048 \\
\hline Normal (6-10) & $528(96.7)$ & $493(91.0)$ & & 908 (92.8) & 139 (88.5) & & 952 (92.8) & 95 (87.2) & \\
\hline Borderline (5) & $11(2.0)$ & $28(5.2)$ & & $42(4.3)$ & $7(4.5)$ & & $43(4.2)$ & $6(5.5)$ & \\
\hline Pathological (0-4) & $7(1.3)$ & $21(3.9)$ & & $28(2.9)$ & $11(7.0)$ & & $31(3.0)$ & $8(7.3)$ & \\
\hline
\end{tabular}

*Established usage: waterpipe or cigarette use once of more times a week. a I47 (4.1\%) students did not answer the question about sex. SDQ: The Strengths and Difficulties Questionnaire. b Cut-off points are shown in brackets next to each category (for self-administered version, http://www.sdqinfo.org). 
Table 3. Distributions of other habits such as alcohol use, drunk and cannabis use based on their degree of consolidation and the Strengths and Difficulties Questionnaire dimensions (SDQ scores) among secondary school students from Seville, Spain, October 2017 ( $N=1135)$

\begin{tabular}{|c|c|c|c|c|c|c|c|c|c|c|}
\hline \multirow[t]{2}{*}{ Difficulties } & \multicolumn{2}{|l|}{ Global } & \multicolumn{2}{|l|}{ Alcohol } & \multicolumn{3}{|c|}{ Drunk or dizzy from alcohol } & \multicolumn{3}{|c|}{ ТнС } \\
\hline & Mean (IQR) & $\begin{array}{c}\text { Not } \\
\text { established } \\
(979 ; \\
86.3 \%) \\
\text { Mean } \\
\text { (IQR) }\end{array}$ & $\begin{array}{c}\text { Established* } \\
\text { (156; } \\
13.7 \%) \\
\text { Mean (IQR) }\end{array}$ & $p$ & $\begin{array}{c}\text { Not } \\
\text { established } \\
\text { (1085; 956\%) } \\
\text { Mean (IQR) }\end{array}$ & $\begin{array}{l}\text { Established * } \\
(50 ; 4.4 \%) \\
\text { Mean (IQR) }\end{array}$ & $p$ & $\begin{array}{l}\text { No } \\
(1018 ; \\
89.7 \%) \\
\text { Mean } \\
\text { (IQR) }\end{array}$ & $\begin{array}{l}\text { Yes } \\
(117 ; \\
10.3 \%) \\
\text { Mean } \\
(\text { IQR) }\end{array}$ & $p$ \\
\hline $\begin{array}{l}\text { Emotional } \\
\text { symptoms }\end{array}$ & $3.0(1.0-4.0)$ & $3.0(1.0-4.0)$ & $3.0(1.5-4.0)$ & 0.278 & $3.0(1.0-4.0)$ & $3.0(2.0-4.0)$ & 0.457 & $3.0(1.0-4.0)$ & $2.0(1.0-5.0)$ & 0.896 \\
\hline $\begin{array}{l}\text { Behavioral } \\
\text { problems }\end{array}$ & $2.0(1.0-3.0)$ & $1.0(0.0-3.0)$ & $2.0(1.0-4.0)$ & 0.0005 & $2.0(1.0-3.0)$ & $3.0(1.0-5.0)$ & 0.0005 & $2.0(0.0-3.0)$ & $3.0(1.0-4.0)$ & 0.0005 \\
\hline Hyperactivity & $4.0(2.0-5.0)$ & $4.0(2.0-5.0)$ & $5.0(3.0-6.0)$ & 0.002 & $4.0(2.0-5.0)$ & $5.0(3.0-6.0)$ & 0.049 & $4.0(2.0-5.0)$ & $4.0(3.0-6.0)$ & 0.002 \\
\hline Peer problems & $1.0(0.0-2.0)$ & $1.0(0.0-2.0)$ & $1.0(0.5-2.0)$ & 0.301 & $1.0(0.0-2.0)$ & $2.0(1.0-3.0)$ & 0.038 & $1.0(0.0-2.0)$ & $2.0(1.0-3.0)$ & 0.0005 \\
\hline $\begin{array}{l}\text { Prosocial } \\
\text { behavior }\end{array}$ & $8.0(7.0-9.0)$ & $9.0(7.0-9.0)$ & $8.0(7.0-9.0)$ & 0.02 & $8.0(7.0-9.0)$ & $8.0(6.0-9.0)$ & 0.033 & $9.0(7.0-9.0)$ & $8.0(7.0-9.0)$ & 0.0005 \\
\hline $\begin{array}{l}\text { Total of } \\
\text { difficulties }\end{array}$ & $10.0(6.0-14.0)$ & $9.0(6.0-13.0)$ & $12.0(7.5-15.0)$ & 0.0005 & $9.0(6.0-14.0)$ & $12.5(9.0-16.0)$ & 0.001 & $9.0(6.0-13.0)$ & $12.0(9.0-15.0)$ & 0.0005 \\
\hline
\end{tabular}

* Established usage: alcohol use or drunk or dizzy from alcohol once or more times a week. THC: use of cannabis. SDQ: The Strengths and Difficulties Questionnaire. IQR: interquartile range (P25-P75).

Table 4. Multivariate model (binary logistic regression) of variables associated to the established usage of cigarettes among secondary school students from Seville, Spain, October 2017 ( $N=1135)$

\begin{tabular}{lcccc} 
Variables & OR & \multicolumn{3}{c}{$95 \%$ CI } \\
& & Lower & Upper & Sig. \\
\hline Age (years) & 1.624 & 1.080 & 2.441 & 0.020 \\
Sex (Ref. female) & 0.470 & 0.258 & 0.856 & 0.014 \\
Established usage of waterpipe & 1.270 & 0.678 & 2.380 & 0.455 \\
Established usage of alcohol & 2.125 & 1.102 & 4.098 & 0.024 \\
Established drunk or dizzy & 2.930 & 1.113 & 7.715 & 0.030 \\
from alcohol ( $\geq 1$ time/week) & & & & \\
Experimentation with cannabis & 10.754 & 4.852 & 23.833 & 0.000 \\
Beliefs consistent with & 1.166 & 0.462 & 2.940 & 0.745 \\
tobacco usage & & & & \\
SD0 emotional symptoms & 0.925 & 0.806 & 1.062 & 0.268 \\
SD0 behavioral problems & 1.028 & 0.858 & 1.230 & 0.767 \\
SD0 hyperactivity & 1.263 & 1.096 & 1.456 & 0.001 \\
SD0 peer problems & 0.858 & 0.697 & 1.058 & 0.152 \\
SD0 prosocial behavior & 0.988 & 0.830 & 1.175 & 0.889 \\
Age of initiating cigarette use & 0.665 & 0.547 & 0.808 & 0.000 \\
Age of initiating waterpipe use & 0.828 & 0.663 & 1.035 & 0.098 \\
Age of initiating alcohol use & 0.994 & 0.800 & 1.234 & 0.956 \\
Age of initiating cannabis use & 1.329 & 0.912 & 1.935 & 0.138 \\
Number of smoking & 1.643 & 1.260 & 2.140 & 0.000 \\
cohabitants (0-6) & & & &
\end{tabular}

lower than in men $(1.8 \%$ vs $5.6 \%$; $=0.005)$; and difficulties in prosocial behaviour was lower in women than in men $(0.6 \%$ vs $1.9 \%$; $=0.005)$. The distribution of score ranges in the SDQ by gender is shown in Table 2).

Delving into other relationships between adolescent strengths and weaknesses and use of substances (SDQ), we saw that the established usage of alcohol, established drunk and established use of cannabis are statistically significantly associated with the overall score of this questionnaire and with the various dimensions of SDQ, with the exception of emotional symptoms (Table 3 ).

The multivariate analysis showed a profile of adolescent associated with established use of cigarettes defined by the increase in age (defined by the course variable $\mathrm{p}=0.0019$ ), cohabitation with smokers $(p=0.275)$, established usage of waterpipe $(p=0.0036)$, established drunk $(p=0.0005)$ and borderline score on the behavioural problem dimension in SDQ $(\mathrm{p}=0.0345)$ (Table 4).

\section{DISCUSSION}

Our study suggests for the first time that adolescents' emotional states and behavioural difficulties are closely related to the established use of WTS and 
cigarettes, as well as other toxic habits (alcohol, drunk and cannabis).

The established usage of waterpipes in our environment is higher than that of cigarettes. This highlights the importance of waterpipe use in the estimation of tobacco use in the adolescent population.

Waterpipe use is associated with more positive attitudes towards it. These consistent attitudes are more frequent among adolescents who consolidate this type of consumption.

Among the adolescents studied, the SDQ overall score is significantly associated $(\mathrm{p}<0.05)$ with all the toxic habits studied, so that the higher the score, the greater the likelihood of established usage of tobacco (water pipe $(\mathrm{p}=0.033)$ or cigarette $(p=0.0001))$, alcohol $(p=0.0005)$, drunk or dizzy from alcohol $(p=0.001)$ and cannabis $(p=0.0005)$. As expressed in our study results, there are sexrelated differences in the SDQ score, particularly regarding emotional symptoms that are significantly more common among women and the difficulties related to behavioural problems and prosocial behaviour that are more common among men. The established usage of waterpipe is related to all dimensions of SDQ, with the highest scores in those students with established use. Concerning the established use of cigarettes, all dimensions, except emotional symptoms, were statistically significantly associated. As for the established use of alcohol, there is a positive association with the highest scores on behavioural and hyperactivity problems and lower scores on prosocial difficulties. In addition, drunk, together with the dimensions described for alcohol, presents a positive association between the consolidation of this habit and the presence of peer problems. Finally, regarding cannabis use, the significant association between all dimensions (except for emotional symptoms) and the use of this substance stands out. Given the results obtained in this study, it would be advisable to screen the emotional and behavioural health of adolescents systematically, not only to treat the emotional problem but to identify those adolescents at increased risk of consolidating toxic habits at an early age.

The established consumers of waterpipe in our study showed more positive attitudes towards its use than unestablished consumers. Cognitive attitudes of established water pipe users: 1) it is less harmful than cigarettes, 2) water filters all toxics, 3) It does not affect passive smokers, 4) it does not create dependence and 5) it does not lead to cigarette smoking (the notion of bridge substance or gateway $)^{8}$. These beliefs are even more meaningful and clinically relevant when related to established cigarette consumers. Results from previous studies also show that waterpipe smokers believe that this form of tobacco use is less harmful than cigarette $\mathrm{use}^{22}$ and that a positive attitude towards the use of waterpipes is associated with a greater likelihood of starting cigarette use. An important finding of our study is that $75 \%$ of respondents seemed unaware of whether waterpipe tobacco packages contained all the information about their potential harm, possibly because, as the authors have already pointed out, users often do not get to see the tobacco package; it is, therefore, important that the health warnings on waterpipe tobacco packages should also be included on the surface of the smoking devices, as otherwise, the user does not get to see these warnings ${ }^{23}$. An analysis of regulations from 62 countries shows that most of them do not have specific regulations on WTS and base the control of tobacco use on legislation on the matter ${ }^{24}$. It seems necessary, therefore, to develop specific regulations on waterpipe tobacco use that cover aspects such as health warnings and consumption devices.

\section{Strengths and limitations}

In our study, the proportion of students living with smokers was $72.1 \%$, well above $41.4 \%$ reported by by the survey on drug use in secondary schools in Spain ESTUDES 2018 study $^{25}$ and even higher than those estimated by this study in 1994 (68.2\%), which may be a limitation as the high proportion of parental models might be leading to increased use among adolescents. Consistent with the literature, our data show a relationship between living with regular smokers and the use of waterpipe tobacco and cigarettes. However, a statistically significant association with the established waterpipe usage was not found, but with cigarettes. In a study conducted on a representative sample from 17 Arab countries, it was found that compared to adolescent children of non-smoker parents, the children of parents who 
smoked cigarettes and waterpipes were more likely to smoke waterpipes or both ${ }^{26}$. Similarly, a secondary analysis of the Global Youth Tobacco Survey, which conducts a meta-analysis of data from 25 countries that included questions about waterpipe use, found that smoker parents were among the factors associated with waterpipe use $\mathrm{e}^{27}$. This association between tobacco use in parents and the increased risk of waterpipe use among their children may contribute to its use being seen by parents as less harmful. Although cultural differences play a very important role, it is worrying that in a study conducted in Qatar among 180 adult waterpipe smokers, $70 \%$ would not mind if their children were to smoke in waterpipes ${ }^{28,29}$.

The established use of cigarettes associated with cohabitation with family smokers has differred by student's sex. A statistically significant association between the female students who lived with family smokers and the established usage of cigarettes was found. Our study has shown that if the teen's mother or sister smokes, the risk of established use of cigarettes statistically significantly increases ${ }^{30,31}$.

All this data shows the importance of family attitudes and habits in the use of waterpipe tobacco by adolescents. Therefore, anti-tobacco campaigns should be aimed at both adolescents and adults.

In our sample, $55.1 \%$ had used a waterpipe once in their lifetime, a much higher number than that reported in the ESTUDES (47.3\%) in other Western countries ( $40 \%$ in London ${ }^{32}, 12 \%$ in $\mathrm{UK}^{33}, 33 \%$ in Sweden $\left.^{34}\right)$.

Controlled by other variables (established waterpipe usage, consistent cognitive attitudes, emotional symptoms, behavioural and peer problems, and difficulties in prosocial behaviour), the likelihood of consolidating cigarette use is determined by age, female sex, established alcohol use and drunk, experimentation with cannabis, hyperactivity, cohabitation with one or more family smokers and early initiation of cigarette use.

Therefore, screening of emotional and behavioural skills and difficulties among adolescents should be established, and preventive activities on substance use should be implemented early in both the students themselves and their families.

One limitation of our study is that it is restricted to teenagers schooled in public schools in the province of Seville, which may reduce the ability to generalize these results.

Although the cross-sectional design of our study cannot answer that question, some of our data suggest that the use of waterpipes precedes and may be the gateway to cigarette use also in our environment: the age in those with established waterpipes usage is lower than those with established cigarette usage. Globally, both the annotated literature and our results suggest that prevention activities regarding waterpipe use should be implemented to reduce their use and to try to close the gateway to cigarette use $\mathrm{e}^{8,35}$.

One aspect to assess in future studies is whether this usage of waterpipes in adolescence is consolidated into adulthood. Although there is no direct data on this, the fact that WTS is associated with nicotine addiction ${ }^{7,36,37}$, raises the possibility that this dependence could lead to a maintenance of waterpipe usage in the future, or that this nicotine dependence will be replaced by cigarette use, since the latter is more accessible. Prospective studies should be designed to prove the hypothesis of WTS as a gateway to cigarette use in adolescents.

\section{CONCLUSIONS}

In conclusion, the results suggest that early use of waterpipe in adolescents poses a risk to the established usage of cigarettes. Similarly, behavioural and emotional difficulties are associated with the established use of tobacco (cigarette and/or waterpipe), alcohol and cannabis.

Smoking prevention programmes should have a more holistic view when addressing addictions as a whole, taking into account, among other factors, adolescents' emotional and behavioural abilities and difficulties, family use and use of other cigaretteassociated substances.

\section{REFERENCES}

1. WHO Study Group on Tobacco Product Regulation (TobReg). Advisory note: Waterpipe Tobacco Smoking: health effects, research needs and recommended actions for regulators. 2nd ed. World Health Organization; 2005. Accessed December 30, 2019. http://apps.who.int/iris/ bitstream/10665/161991/1/9789241508469_eng.pdf

2. WHO Study Group on Tobacco Product Regulation (TobReg). Waterpipe Tobacco Smoking: Health Effects, Research, Needs and Recommended Actions by Regulators. Advisory Note (2a Ed). 2a. (Organización Mundial de la 
Salud, ed.). Ginebra, Suiza; 2015. http://apps.who.int/ iris/bitstream/10665/161991/1/9789241508469_eng. pdf

3. Pratiti R, Mukherjee D. Epidemiology and Adverse Consequences of Hookah/Waterpipe Use: A Systematic Review. Cardiovasc Hematol Agents Med Chem. 2019;17(2):82-93. do i:10.2174/1871525717666190904151856

4. Qasim H, Alarabi AB, Alzoubi KH, Karim ZA, Alshbool FZ, Khasawneh FT. The effects of hookah/waterpipe smoking on general health and the cardiovascular system. Environ Health Prev Med. 2019;24(1):58. doi:10.1186/s12199-019-0811-y

5. Bhatnagar A, Maziak W, Eissenberg T, et al. Water Pipe (Hookah) Smoking and Cardiovascular Disease Risk: A Scientific Statement From the American Heart Association. Circulation. 2019;139(19):e917-e936. doi:10.1161/CIR.0000000000000671

6. Aboaziza E, Eissenberg T. Waterpipe tobacco smoking: what is the evidence that it supports nicotine/tobacco dependence? Tob Control. 2015;24(Suppl 1):i44-i53. doi:10.1136/tobaccocontrol-2014-051910

7. Bahelah R, DiFranza JR, Ward KD, et al. Waterpipe smoking patterns and symptoms of nicotine dependence: The Waterpipe Dependence in Lebanese Youth Study. Addict Behav. 2017;74:127-133. doi:10.1016/j.addbeh.2017.06.003

8. Al Oweini D, Jawad M, Akl EA. The association of waterpipe tobacco smoking with later initiation of cigarette smoking: a systematic review and meta-analysis exploring the gateway theory. Tob Control. 2019;29:577584. doi:10.1136/tobaccocontrol-2018-054870

9. Centers for Disease Control and Prevention. Tobacco product use among middle and high school students-United States, 2011 and 2012. MMWR Morb Mortal Wkly Rep. 2013;62(45):893-897. Accessed March 29, 2021. https://www.ncbi.nlm.nih.gov/pmc/articles/ PMC4585347/pdf/893-897.pdf

10. Primack BA, Carroll MV, Weiss PM, et al. Systematic Review and Meta-Analysis of Inhaled Toxicants from Waterpipe and Cigarette Smoking. Public Health Rep. 2016;131(1):76-85. doi:10.1177/003335491613100114

11. Maziak W, Ben Taleb Z, Jawad M, et al. Consensus statement on assessment of waterpipe smoking in epidemiological studies. Tob Control. 2017;26(3):338343. doi:10.1136/tobaccocontrol-2016-052958

12. Moreno C, Ramos P, Rivera F, et al. La adolescencia en España: salud, bienestar, familia, vida académica y social: Resultados del E studio HBSC 2018. Ministerio de Sanidad, Consumo y Bienestar Social; 2020. Accessed March 29, 2021. https://www.mscbs.gob.es/ profesionales/saludPublica/prevPromocion/promocion/ saludJovenes/estudioHBSC/docs/HBSC2018/ HBSC2018_ResultadosEstudio.pdf

13. Maziak W, Taleb ZB, Bahelah R, et al. The global epidemiology of waterpipe smoking. Tob Control. 2015;24(Suppl 1):i3i12. doi:10.1136/tobaccocontrol-2014-051903
14. Azagba S, Latham K, Shan L. Waterpipe tobacco smoking trends among middle and high school students in the United States from 2011 to 2017. Drug Alcohol Depend. 2019;200:19-25. doi:10.1016/j.drugalcdep.2019.04.005

15. Poton WL, Soares ALG, Gonçalves H. Problemas de comportamento internalizantes e externalizantes e uso de substâncias na adolescência. Internalizing and externalizing behavior problems and substance use in adolescence. Article in Portuguese. Cad Saude Publica. 2018;34(9):e00205917. doi:10.1590/0102-311X00205917

16. Ramji R, Arnetz BB, Nilsson M, et al. Waterpipe use in adolescents in Northern Sweden: Association with mental well-being and risk and health behaviours. Scand J Public Health. 2018;46(8):867-876. doi:10.1177/1403494817746534

17. Goodman R. The Strengths and Difficulties Questionnaire: a research note. J Child Psychol Psychiatry. 1997;38(5):581586. doi:10.1111/j.1469-7610.1997.tb01545.x

18. Ortuño-Sierra J, Chocarro E, Fonseca-Pedrero E, Riba SSI, Muñiz J. The assessment of emotional and Behavioural problems: Internal structure of The Strengths and Difficulties Questionnaire. Int J Clin Health Psychol. 2015;15(3):265-273. doi:10.1016/j.ijchp.2015.05.005

19. Ortuño-Sierra J, Fonseca-Pedrero E, Paino M, Sastre i Riba S, Muñiz J. Screening mental health problems during adolescence: psychometric properties of the Spanish version of the Strengths and Difficulties Questionnaire. J Adolesc. 2015;38:49-56. doi:10.1016/j.adolescence.2014.11.001

20. Gómez-Beneyto M, Nolasco A, Moncho J, et al. Psychometric behaviour of the strengths and difficulties questionnaire (SDQ) in the Spanish national health survey 2006. BMC Psychiatry. 2013;13:95. doi:10.1186/1471-244X-13-95

21. SDQ: Information for researchers and professionals about the Strengths \& Difficulties Questionnaires. sdqinfo.org. Accessed April 3, 2017. https://www.sdqinfo.org/

22. Amin TT, Amr MA, Zaza BO, Kaliyadan F. Predictors of waterpipe smoking among secondary school adolescents in Al Hassa, Saudi Arabia. Int J Behav Med. 2012;19(3):324-335. doi:10.1007/s12529-011-9169-2

23. Jawad M, Bakir A, Ali M, Grant A. Impact of Waterpipe Tobacco Pack Health Warnings on Waterpipe Smoking Attitudes: A Qualitative Analysis among Regular Users in London. Biomed Res Int. 2015;2015:1-6. doi:10.1155/2015/745865

24. Jawad M, El Kadi L, Mugharbil S, Nakkash R. Waterpipe tobacco smoking legislation and policy enactment: a global analysis. Tob Control. 2015;24(Suppl 1):i60-i65. doi:10.1136/tobaccocontrol-2014-051911

25. Observatorio Español de las Drogas y las Adicciones. Encuesta Sobre Uso de Drogas En Enseñanzas Secundarias En España (ESTUDES) 1994-2018. Ministerio de Sanidad, Consumo y Bienestar Social; 2018. ESTUDES 2018/19. Accessed March 29, 2021. https:// 
pnsd.sanidad.gob.es/profesionales/sistemasInformacion/ sistemaInformacion/pdf/ESTUDES_2018-19_Informe. pdf

26. Veeranki SP, Alzyoud S, Dierking L, et al. Associations of Adolescents' Cigarette, Waterpipe, and Dual Tobacco Use With Parental Tobacco Use. Nicotine Tob Res. 2016;18(5):879-884. doi:10.1093/ntr/ntv224

27. Jawad M, Lee JT, Millett C. Waterpipe Tobacco Smoking Prevalence and Correlates in 25 Eastern Mediterranean and Eastern European Countries: Cross-Sectional Analysis of the Global Youth Tobacco Survey. Nicotine Tob Res. 2016;18(4):395-402. doi:10.1093/ntr/ntv101

28. Jaam M, Al-Marridi W, Fares H, Izham M, Kheir N, Awaisu A. Perception and intentions to quit among waterpipe smokers in Qatar: a cross-sectional survey. Public Health Action. 2016;6(1):38-43. doi:10.5588/pha.15.0054

29. Schröder C, Chaaya M, Saab D, Mahfoud Z. The determinants of intention to smoke waterpipe among adolescents in Lebanon: a national household survey. J Public Health (Oxf). 2016;38(1):84-91. doi:10.1093/pubmed/fdv004

30. Baheiraei A, Shahbazi Sighaldeh S, Ebadi A, Kelishadi R, Majdzadeh R. The Role of Family on Hookah Smoking Initiation in Women: A Qualitative Study. Glob J Health Sci. 2015;7(5):1-10. doi:10.5539/gjhs.v7n5p1

31. Ramji R, Nilsson M, Arnetz B, Wiklund Y, Arnetz J. Taking a Stand: An Untapped Strategy to Reduce Waterpipe Smoking in Adolescents. Subst Use Misuse. 2019;54(3):514-524. do i: $10.1080 / 10826084.2018 .1521429$

32. Jawad M, Power G. Prevalence, correlates and patterns of waterpipe smoking among secondary school students in southeast London: a cross-sectional study. BMC Public Health. 2016;16:108. doi:10.1186/s12889-016-2770-1

33. Jawad M, McIver C, Iqbal Z. Prevalence and correlates of lifetime waterpipe, cigarette, alcohol and drug use among secondary school students in Stoke-on-Trent, UK: a post hoc cross-sectional analysis. J Public Health (Oxf). 2014;36(4):615-621. doi:10.1093/pubmed/fdu002

34. Ramji R, Arnetz J, Nilsson M, et al. Determinants of waterpipe use amongst adolescents in Northern Sweden: a survey of use pattern, risk perception, and environmental factors. BMC Res Notes. 2015;8:441. doi:10.1186/s13104-015-1413-4

35. Treur JL, Rozema AD, Mathijssen JJP, van Oers H, Vink JM. E-cigarette and waterpipe use in two adolescent cohorts: cross-sectional and longitudinal associations with conventional cigarette smoking. Eur J Epidemiol. 2018;33(3):323-334. doi:10.1007/s10654-017-0345-9

36. Jaber R, Madhivanan P, Veledar E, Khader Y, Mzayek F, Maziak W. Waterpipe a gateway to cigarette smoking initiation among adolescents in Irbid, Jordan: a longitudinal study. Int J Tuberc Lung Dis. 2015;19(4):481-487. doi:10.5588/ijtld.14.0869

37. Jensen PD, Cortes R, Engholm G, Kremers S, Gislum M. Waterpipe use predicts progression to regular cigarette smoking among Danish youth. Subst Use Misuse. 2010;45(7-8):1245-1261. doi:10.3109/10826081003682909

\section{ACKNOWLEDGEMENTS}

To the secondary schools belonging to the Territorial Delegation of Education of Seville: IES Torre de los Guzmanes of the municipality of La Algaba, IES de Castilblanco de los Arroyos and IES Gerena. To the psychologist of the Addiction Treatment Centre of Gerena City Council: Ruperto Piñero Cabanillas.

\section{CONFLICTS OF INTEREST}

The authors have completed and submitted the ICMJE Form for Disclosure of Potential Conflicts of Interest and none was reported.

\section{FUNDING}

There was no source of funding for this research.

\section{ETHICAL APPROVAL AND INFORMED CONSENT}

The study was approved by ethics committees of the Virgen Macarena and Virgen del Rocío University Hospitals in Seville (1484-N-16). The participating Secondary School Boards and the association that represents the parents of students, consented to carry out the research.

\section{DATA AVAILABILITY}

The data supporting this research is available from the authors on reasonable request.

\section{AUTHORS' CONTRIBUTIONS}

JMS-L: Conceptualization-Lead, Data curation-Equal, Formal analysisEqual, Investigation-Equal, Methodology-Equal, Project administrationEqual, Resources-Equal, Software-Equal, Supervision-Lead, Validation-Lead, Visualization-Equal, Writing-original draft-Equal, Writing-review \&t editingEqual. FR-V: Conceptualization-Supporting, Data curation-Supporting, Formal analysis-Supporting, Supervision-Equal, Writing-original draft-Equal, Writing-review \&t editing-Equal. LGL-R: ConceptualizationEqual, Data curation-Lead, Formal analysis-Lead, Investigation-Equal, Methodology-Lead, Project administration-Equal, Resources-Equal, Software-Lead, Supervision-Equal, Validation-Equal, Visualization-Equal, Writing-original draft-Equal, Writing-review \&t editing-Equal.

\section{PROVENANCE AND PEER REVIEW}

Not commissioned; externally peer reviewed. 